\title{
Competing views of information: human right vs. commodity, private vs. shared property
}

\section{J. Carlos Fernández-Molina}

Facultad de Comunicación y Documentación, Universidad de Granada, España; jcfernan@ugr.es

\begin{abstract}
Two competing perspectives of information are analyzed. Information may be considered as a human right, meaning all people should have access to it regardless of their economic power, or as a commodity, only accessible for those who are able to pay for it. In the same vein, the dichotomy between private or shared property of information is examined, particularly meaningful in the field of intellectual property and copyright legislation.
\end{abstract}

Keywords: Information, human rights, commodity, private property, shared property

Acknowledgement: This study was supported by the Spanish Ministry of Science and Innovation (Project CSO-200803817/SOCl)

A pproximations to the concept of information have been numerous, stemming from an array of disciplines. Yet the many attempts to distinguish information from its conceptual neighbours data, facts, knowledge, intelligence, communication, messages, understanding or signs - have tended toward failure. There are so many ways to communicate information, and so many things to communicate (mentally, acoustically, genetically, mechanically, electrically, and so on) that it hardly seems appropriate to use one single term of reference. In this sense, Fairthorne (1967) pointed out that the use of words such as "information" is merely metaphorical, providing a simple and convenient tag for an amorphous mass of poorly defined activities or phenomena.

The conceptual search for "information" may depart from a scientific standpoint, that is, aiming to arrive at a unique concept that would fulfil a series of requirements for constituting "information science"; or traverse a pragmatic focus, aspiring only to find those aspects of the term "information" that are of use to us. The latter is the road taken, for instance, by Buckland (1991), who distinguishes between: a) information as a process: the action of informing, communication of knowledge; b) information as knowledge: that which is imparted in the informative process, reducing uncertainty; and c) information as a thing: objects such as data or documents that contain information, that possess the capacity for imparting knowledge or communicating information. If we adopt this last perspective, we also encounter conflicting views, however. Namely, the possibility of considering information as a human right, implying that all human beings should have access to it regardless of their economic capacity; or else the understanding that information is a simple commodity and is therefore subjected to the laws of the marketplace. This division leads us to a further crossroads: whether information should come under a regime of private property, or rather, it would be more appropriate to share in its ownership. This crux of notions, economic and social (Savolainen, 1990; Raban, 2008), stands at the core of any discussion or study of information.

\section{Human right or commodity?}

The right to information is one of the most basic human rights, and is acknowledged as such in article 19 of the Universal Declaration 
of Human Rights (United Nations, 1948). Accordingly, free and public access to information for all is one of the basic principals of Librarianship, configuring an ethical foundation for the sector of public libraries and, though to a lesser degree, academic libraries. For this reason, numerous public and professional declarations (UNESCO, 1994) make very clear mention of it. Yet free access cannot be understood in absolute terms. There are nuances and connotations that must be brought forth. For one: if professional librarians place full emphasis on the "free" aspect (in the sense of "at no cost"), the chances of survival are reduced for those information centres that have limited funding. There are two sides to the coin, then. On the one hand, social responsibility dictates that access to information should be free as long as it is relevant for the legitimate objectives of the citizen (Sally, 2001). This of course leads us to ask: And what is relevant? Education and science? Or fiction and entertainment as well? Meanwhile, others claim that only a small portion of information should be provided at no cost, while the rest would carry a price, given that the survival of the organization providing information depends on such fees; aside from keeping the library alive or prosperous, this prevents the frivolous use of resources and enhances respect for the institution and librarians in general (Anderson, 1999). What would appear evident is that the price of information is a main factor determining its accessibility (Ponelis, 2007), for which reason it wields great influence on the well-being of citizens (Alfino \& Pierce, 1997). But we have yet to resolve the matter of which information should be free and which should not. As Capurro (2001) underlines, this is both a social and an individual problem. Thus, the objective of creating a context of egalitarian access to information, avoiding the digital divide, is a social one... but it leads to a blurred vision of access to information as something social and not an individual right. Himma (2007), in turn, holds that information has an intrinsic value, and that an authentic moral right to information can be said to exist and pertain to all human beings.

\section{Private or shared property?}

Two basic characteristics allow us to distinguish between public goods and private goods: exclusiveness, that is, the ownership of a good interferes with its use or consumption by another party; and rivalry, by virtue of which possession and use by one person reduces the possibility of use by another. Purely private goods have both these characteristics, whereas purely public goods have neither, their use involving no rivalry or exclusivity. Of course there are also many mixed situations, involving one aspect or the other. Such is the case of information, as its use by others may be excluded, for instance through copyright legislation, although its use by one person does not interfere with its availability for others. Stated in economic terms, the marginal cost of allowing another person to access and consume information is zero.

On more practical terrain, there exists information of a public nature, but also that of a private nature. This dichotomy has a strong battlefront in the area of copyright legislation, where regulation of certain uses of information (sometimes involving payment as well) depends on authorization by the holders of copyright, while other uses may be made without permission or payment. As a consequence of technological advances in recent years, this traditional battle between the concepts of private information and shared information is being fought with greater zeal. We have seen significant reforms in copyright legislation in both the national and international realms, whose final outcome is a higher level of protection for the rightholders, and a fortified conception of information as merchandise. Yet at the same time, a strong contrary force has emerged and branched out, in favour of treating information as a public good, to be shared freely.

The Copyright Treaty of the World Intellectual Property Organization (WIPO, 1996) set forth the model to be followed by all countries in reforming their respective national laws in order to adapt them to the new technological setting. This treaty broadened the classical "right of communication to the public" so as to cover access and any transmission of digital information via Internet. Accordingly, its article 8 establishes that the authors hold "the 
exclusive right of authorizing any communication to the public of their works, by wire or wireless means, including the making available to the public of their works in such a way that members of the public may access these works from a place and at a time individually chosen by them". This inclusion of "making available to the public" a work can be seen as an extension of the traditional right to public communication, which now encompasses a vast array of activities involving the transmission of information over the Internet. Furthermore, new legal backing of traditional protection was introduced in the text: article 11 requires that national copyright legislation "provide adequate legal protection and effective legal remedies against the circumvention of effective technological measures that are used by authors in connection with the exercise of their rights". This means that technological measures implanted by rightholders, for example anticopy or controlled access systems, must be protected legally so that their circumvention or neutralization could be considered an infraction of the law. In short, the legal protection of copyright is enhanced and gains an additional protective layer, technological cover, in turn protected by legislation, giving rise to intensive control of digital works (Fernández-Molina, 2003).

Meanwhile, the movement in favour of free and shared use of information (embracing all the "copyleft" initiatives) arises in reaction to the excessive fortification of copyright norms, with the aim to take advantage of the plentiful possibilities that the digital setting offers for generating, sharing, integrating and distributing information. Depending upon the specific objective at hand, this trend may adopt different strategies. The pioneering force was probably that of free software, with the underlying notion that software can be used, copied, studied, modified and redistributed freely. Inspired by this movement, the "creative commons" licences were engendered, with Lawrence Lessig (2003) as the figure of reference, and the overall aim of eliminating obstacles that hinder creativity, while facilitating the use and distribution of digital contents for the general public. This stands as a restitution of power to the authors, who can employ the new technologies to disseminate their works under licences that are flexible enough to let the author decide which uses might be allowed (and which are not), in substitution of the classic and overly restrictive "all rights reserved". An equally interesting prospect, especially for the world of education and research, is that of the "open access" movement, aspiring towards free, immediate, unrestricted access to educational or researchrelated material through open access journals and digital archives or repositories. Here we encounter the concept of "information commons" (Kranich \& Schement, 2008), likewise oriented toward the social benefits of sharing knowledge and liberating its usage. The term "commons" evokes an old English tradition by which farmers could share rights and responsibilities regarding certain sections of land for cultivation or pasture. A similar notion of common good would urge strengthening the public domain (Benkler, 1999; Boyle, 2003).

\section{Conclusion}

This discussion of opposing views of information is not intended as a mere theoretical-philosophical exercise. To the contrary, it has important consequences and implications for the everyday lives of people in general. Resolution of the many conflicting notions put forth here should come from policy-makers who have the best interest of the community in mind. For example, some decisions must be made as to whether society benefits from information being used by a lesser number of persons, who are willing and able to pay for it as a simple private good.

One illustrative example of this dilemma can be found in the digital divide. Its elimination, or reduction, is probably one of the main objectives of information policymakers, both nationwide and internationally. However, we face growing evidence that information is considered to be a simple commodity, and as such is excessively protected by copyright legislation. This trend entails greater difficulties in accessing information, and in the human acquisition of knowledge, a matter that is crucial for developing countries as net importers of these goods. 


\section{References}

Alfino, M. \& Pierce, I. (1997). Information ethics for librarians. Jefferson, NC.: McFarland.

Anderson, R. (1999). The debate over service fees: What was the question again? Library Collections, Acquisitions, and Technical Services, 23(2), 183-190.

Benkler, Y. (1999). Free as the open air: First Amendment constraints on enclosure of the public domain. New York University Law Review, 74, 354-446.

Boyle, J. (2003). The second enclosure movement and the construction of the public domain. Law and Contemporary Problems, 66(1/2), 33-74.

Buckland, M. K. (1991). Information as thing. Journal of the American Society for Information Science, 42(5), 351-360.

Capurro, R. (2001). Ethics and information in the digital age. LIDA 2001 Annual Course and Conference Libraries in the Digital Age (Dubrovnik, Croatia, 23-27 May, 2001), http://www.ffzg.hr/infoz/lida/lida2001/present/capurro.doc

Fairthorne, R. A. (1967). The morphology of "information flow. Journal of the Association for Computing Machinery, 14(4), 710-719.

Fernández-Molina, J.C. (2003). Laws against the circumvention of copyright technological protection. Journal of Documentation, 59(1), 41-68.

Himma, K.E. (2007). Foundation issues in information ethics. Library Hi Tech, 25(1), 79-94.

Kranich, n. \& Schement, J.R. (2008). Information commons. Annual Review of Information Science and Technology, 42 , 547-591.

Lessig, L. (2003). The creative commons. Florida Law Review, 55, 763-777.

Ponelis, S.R. (2007). Implications of social justice for the pricing of information goods. International Review of Information Ethics, 7, 216-220, http://www.i-r-i-e.net/inhalt/007/23-ponelis.pdf

Raban, D.R. (2008). The incentive structure in an online information market. Journal of the American Society for Information Science and Technology, 59(14), 2284-2295.

Sally, D.M. (2001). Prostitution, simony, and fees for service: Walzer's theory of justice and a defense of communally funded information against the tyranny of the marketplace. Library Quarterly, 71(3), 330-359.

Savolainen, R. (1990). Fee or free? The socio-economic dimensions of the charging dilemma. Journal of Information Science, 16(3), 143-153.

UNESCO (1994). UNESCO Public Library Manifesto, http://www.unesco.org/webworld/libraries/manifestos/libraman.html

United Nations (1948). Universal Declaration of Human Rights, http://www.unhchr.ch/udhr/lang/eng.pdf

WIPO (1996). WIPO Copyright Treaty (adopted in Geneva on December 20, 1996), http://www.wipo.int/export/sites/www/treaties/en/ip/wct/pdf/trtdocs wo033.pdf

\section{About the Author}

J. Carlos Fernández-Molina

is Associate Professor at the Faculty of Communication and Information Studies, University of Granada, Spain. He holds degrees in law, and library and information science and a $\mathrm{PhD}$ in information science. His main research areas include legal issues of information, information ethics, knowledge organization and theoretical aspects of information science. 